\title{
REKAYASA PERANGKAT LUNAK MONITORING DAN PELAPORAN KEBERSIHAN DAN PERTAMANAN KOTA PALEMBANG DENGAN TEKNOLOGI MOBILE CROSS PLATFORM
}

\author{
Rachman Kurniawan ${ }^{1}$ \\ ${ }^{1}$ Fakultas Teknik Ilmu Komputer, Universitas Bina Darma, Palembang, 30264, Indonesia \\ E-mail: officially.yuliandp@gmail.com ${ }^{1}$
}

\begin{abstract}
Information Technology (IT), or in English known as Information technology (IT) is a general term for any technology that helps humans create, change, store, communicate and / or disseminate information. In this modern era, competition in all fields is very fierce, therefore the need for very important information to support one's activities is very much needed. The Sanitation and Gardening Service of Palembang City is a regional apparatus as an implementing element for regional government administration which has the main task of carrying out part of the affairs in the field of cleanliness and gardening. At this time, the monitoring (patrol) carried out by the Sanitation and Gardening Office of Palembang City is carried out every working day. The patrol's targets include environmental cleanliness and the beauty of landscaping, and always maintaining landscaping so that it looks beautiful throughout the city of Palembang. Realizing a different reporting concept certainly requires a development, so that the reporting objectives can be achieved, and the results of cleaning and gardening reporting also increase. development of reporting that is tailored to the needs and cleanliness of the park, so that it leads to the satisfaction of employees who wish to report quickly and accurately. Development of monitoring software and reporting of landscaping cleanliness in the city of Palembang using cross platform android technology which can be implemented on Android, IOS and Windows based cellphones.
\end{abstract}

Keywords: Information Technology, Android, Mobile Cross Platform Technology

\begin{abstract}
Abstrak
Teknologi Informasi (TI), atau dalam bahasa Inggris dikenal dengan istilah Information technology (IT) adalah istilah umum untuk teknologi apa pun yang membantu manusia dalam membuat, mengubah, menyimpan, mengomunikasikan dan/atau menyebarkan informasi. Di era modern ini tentunya persaingan dalam segala bidang sangat ketat, maka dari itu kebutuhan akan informasi yang sangat penting untuk mendukung aktivitas seseorang sangat dibutuhkan. Dinas Kebersihan dan Pertamanan Kota Palembang merupakan perangkat daerah sebagai unsur pelaksana penyelenggaraan pemerintah daerah yang mempunyai tugas pokok melaksanakan sebagaian urusan dibidang kebersihan dan pertamanan. Pada saat ini proses monitoring (patroli) yang dilakukan oleh Dinas Kebersihan dan Pertamanan Kota Palembang dilaksanakan setiap hari kerja. Sasaran patroli meliputi kebersihan lingkungan dan keindahan pertamanan selalu terjaga dan tata pertamanan agar terlihat asri di seluruh area kota Palembang. Dalam mewujudkan konsep pelaporan yang berbeda tentu membutuhkan suatu pengembangan, sehingga tujuan pelaporan dapat tercapai dan hasil pelaporan kebersihan dan pertamanan ikut meningkat. pengembangan pelaporan yang disesuaikan dengan kebutuhan dan kebersihan pertamanan, sehingga hal tersebut berujung pada kepuasaan pegawai yang ingin melakukakn pelaporan secara cepat dan tepat. Pengembangan perangkat lunak monitoring dan pelaporan kebersihan pertamanan di kota palembang dengan menggunakan teknologi android cross platform yang dapat diimplementasikan pada handhone berbasis android, IOS dan Windows.
\end{abstract}

Kata Kunci: Teknologi Informasi, Android, Teknolgi Mobile Cross Platform 


\section{Pendahuluan}

Teknologi Informasi (TI), atau dalam bahasa Inggris dikenal dengan istilah Information technology (IT) adalah istilah umum untuk teknologi apa pun yang membantu manusia dalam membuat, mengubah, menyimpan, mengomunikasikan dan/atau menyebarkan informasi. Di era modern ini tentunya persaingan dalam segala bidang sangat ketat, maka dari itu kebutuhan akan informasi yang sangat penting untuk mendukung aktivitas seseorang sangat dibutuhkan.

Dinas Kebersihan dan Pertamanan Kota Palembang merupakan perangkat daerah sebagai unsur pelaksana penyelenggaraan pemerintah daerah yang mempunyai tugas pokok melaksanakan sebagaian urusan dibidang kebersihan dan pertamanan. Kebersihan merupakan bagi keindahan untuk pertamanan kota dan menjadi kebutuhan pusat kota untuk melihat kebersihan kota karena lebih baik akan terciptanya keindahan di kota serta dalam nyaman, sehingga perlunya kebersihan dalam pertamanan kota yang menjadi pusat kenyamanan kota palembang.

Pada waktu ini proses monitoring (patroli) yang dilakukan oleh Dinas Kebersihan dan Pertamanan Kota Palembang dilaksanakan setiap hari kerja. Sasaran patroli meliputi kebersihan lingkungan dan keindahan pertamanan selalu terjaga dan tata pertamanan agar terlihat asri di seluruh area kota Palembang. Dinas Kebersihan dan Pertamanan Kota Palembang dalam menjalankan monitoring (patroli) belum menggunakan Teknologi Informasi dalam menunjang kegiatan monitoring mereka. Pelaporan khususnya kebersihan dan pertamanan kota palembang saat ini perlu melakukan berbagai perubahan dalam proses pelaporan, salah satunya adalah dengan menerapkan konsep pelaporan teknologi mobile yang bersifat berbeda, dimana dalam pelaporan tersebut masyarakat dapat memberikan informasi yang akurat dan pihak Dinas Kebersihan dan Pertamanan Kota Palembang dapat mengecek ke lokasi yang diperoleh dari masyarakat.

Dalam mewujudkan konsep pelaporan yang berbeda tentu membutuhkan suatu pengembangan, sehingga tujuan pelaporan dapat tercapai dan hasil pelaporan kebersihan dan pertamanan ikut meningkat. pengembangan pelaporan yang disesuaikan dengan kebutuhan dan kebersihan pertamanan, sehingga hal tersebut berujung pada kepuasaan pegawai yang ingin melakukakn pelaporan dalam memahami pelaporan teknologi mobile secara cepat dan tepat.

\section{Metodologi Penelitian}

Metode yang digunakan dalam penelitian ini yaitu metode rekayasa. Penelitian rekayasa adalah penelitian yang menerapkan ilmu pengetahuan menjadi suatu rancangan guna mendapatkan kinerja sesuai dengan persyaratan yang ditentukan

\subsection{Metode Pengumpulan Data}

Penelitian ini menggunakan metode pengumpulan data antara lain adalah sebagai berikut :

1. Data primer

a. Observasi, Observasi merupakan cara atau metode menghimpun keterangan atau data yang dilakukan dengan mengadakan pengamatan dan pencatatan secara sistematis terhadap fenomena yang sedang dijadikan sasaran pengamatan.

b. Wawancara, Wawancara adalah proses memperoleh keterangan untuk tujuan penelitian dengan cara tanya jawab dan bertatap muka antara pewawancara dan informan atau orang yang diwawancarai. Dalam penelitian ini, peneliti melakukan wawancara dengan salah sat satu staff dinas Kebersihan dan Pertamanan Kota Palembang

2. Data sekunder

a. Dokumentasi, Peneliti melakukan penelitian menggunakan data bukti atau laporan dalam arsip (Dokumen dyang dipublikasikan atau tidak dipublikasi) 
b. Data yang didapat dan digunakan berupa pengetahuan yang didapat dari bahan-bahan kuliah, browsing internet atau buku yang berhubungan dengan penelitian ini

\subsection{Metodologi Pengembangan Sistem}

Pengembangan sistem dalam penelitian ini menggunakan metode Rational Unified Process (RUP). Menurut (Sukamto, \& Shalahuddin 2013), RUP (Rational Unified Process) adalah pendekatan pengembangan perangkat lunak yang dilakukan berulang-ulang (iterative), fokus pada arsitektur (architecture-centric), lebih diarahkan berdasarkan penggunaan kasus (use case driven). Dengan menggunakan model ini, RUP membagi tahapan pengembangan perangkat lunaknya ke dalam 4 fase sebagai berikut:

1. Inception, Pada tahap ini penulis mendefinisikan batasan kegiatan, melakukan analisis kebutuhan pengguna, melakukan perancangan awal perangkat lunak, pemodelan diagram UML (use case diagram), dan pembuatan dokumentasi.

2. Elaboration, Tahap untuk melakukan desain secara lengkap berdasarkan hasil analisis ditahap inception.

3. Construction, Tahap untuk mengimplementasikan hasil dan melakukan pengujian hasil implementasi.

4. Transition, Tahap untuk menyerahkan sistem ke konsumen (roll-out), yang umumnya mencakup pelaksanaan pelatihan kepada pengguna dan testing beta aplikasi terhadap ekspetasi pengguna.

Tahapan pengembangan sistem pada metode RUP (Rational Unified Process ) yang dapat dilakukan secara interative yaitu :

\section{Inception (Permulaan)}

Tahap ini merupakan tahap untuk mengidentifikasi sistem yang akan dikembangkan. Tahap ini menentukan ruang lingkup dari proyek, melakukan analisis kebutuhan user, analisis kebutuhan fungsional, dan pemodelan diagram UML.

a. Ruang Lingkup Dari Proyek

Ruang lingkup dari aplikasi yang dibuat adalah sebagai berikut:

a. Sebuah sistem yang dirancang adalah fokus pelaporan kegiatan rutin pegawai pada sub bidang kebersihan dan pertamanan

b. Untuk mengatur data mecakup keseluruhan yang tersimpan dalam database.

c. Analisis Kebutuhan User

Tabel 1. Ruang Lingkup

\begin{tabular}{|l|l|l|}
\hline Kategori & Tugas & Hak Akses Aplikasi \\
\hline Admin & 1. Menginputkan data kelurahan & $\begin{array}{l}\text { Mempunyai hak akses sebagai } \\
\text { pengguna dalam system }\end{array}$ \\
& 2. Menginputkan kecamatan & \\
& 3. Menginputkan kegiatan rutin & \\
& 5. Menginputkan data petugas pemantau & \\
\hline
\end{tabular}

\section{d. Analisis Kebutuhan Fungsional}

Tabel 2. Kebutuhan Fungsional

\begin{tabular}{|l|l|}
\hline SKPL ID & Deskripsi \\
\hline SKPL 01 & Aplikasi mampu untuk login dan logout \\
\hline SKPL 02 & Aplikasi mampu menginput atau mengedit data kelurahan \\
\hline SKPL 03 & Aplikasi mampu menginput dan mengedit data kecamatan \\
\hline SKPL 04 & Aplikasi mampu menginput dan mengedit data kegiatan rutin \\
\hline SKPL 05 & Aplikasi melakukan proses menginput petugas pemantau \\
\hline SKPL 06 & Aplikasi melakukan proses menginput \\
\hline
\end{tabular}




\section{e. Analisis Kebutuhan Nonfungsional}

\begin{tabular}{|l|l|}
\multicolumn{2}{|c|}{ Tabel 2. Kebutuhan Nonfungsional } \\
\hline SKPL ID & Deskripsi \\
\hline SKPL 01 & Aplikasi hanya dapat dioperasikan oleh admin \\
\hline SKPL 02 & Aplikasi dapat menyimpan data secara otomaatis \\
\hline SKPL 03 & Aplikasi dapat diakses selama 24 jam \\
\hline SKPL 04 & Aplikasi dapat memiliki system yang menarik \\
\hline
\end{tabular}

\section{f. Pemodelan Diagram UML}

Diagram UML digunakan untuk melakukan spesifikasi, visualisasi dan dokumentasi artifak dari software system. Berikut diagram usecasenya.

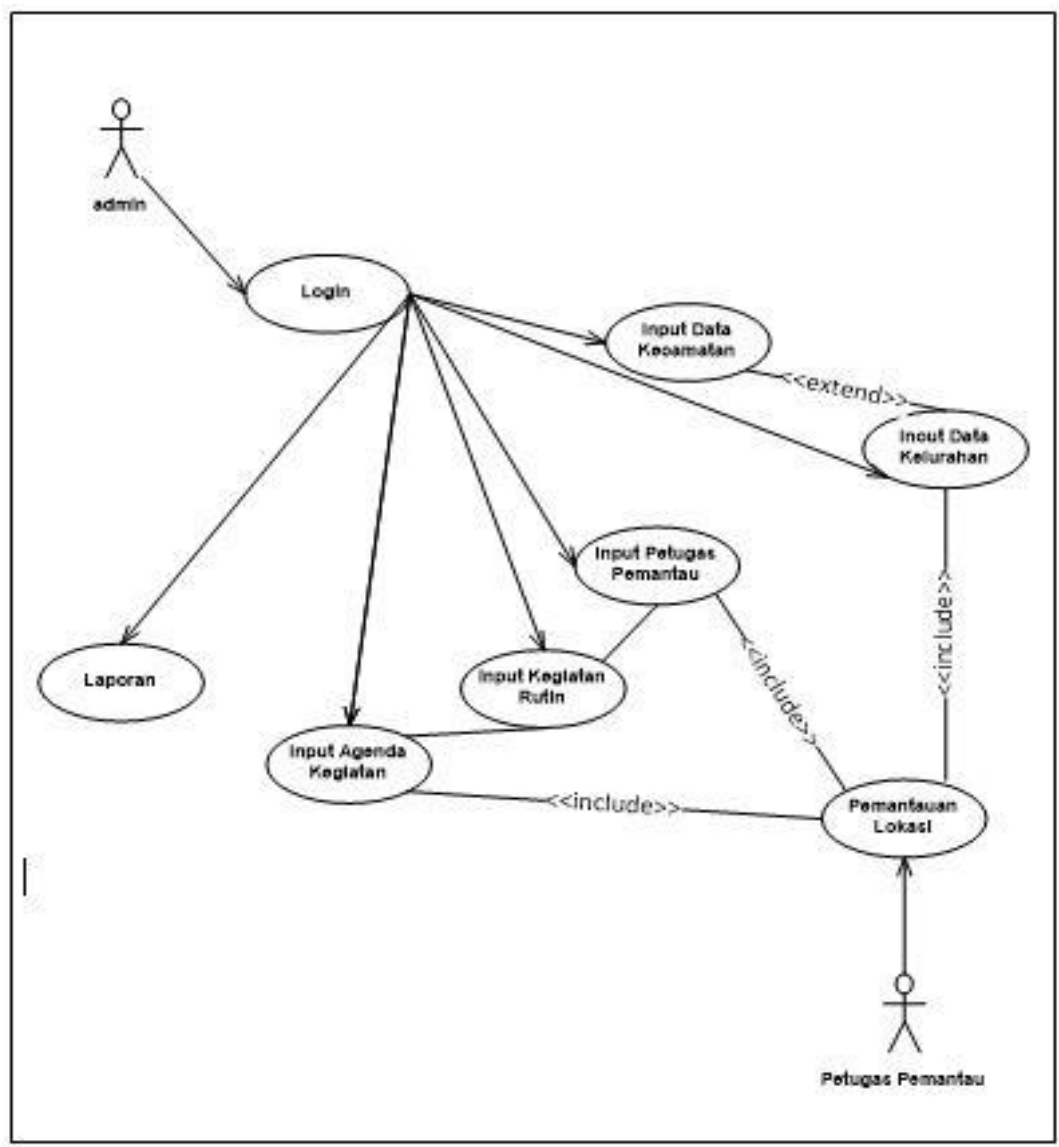

Gambar 1. Use Case Diagram

Dari gambar use case diatas dapat dijelaskan sebagai berikut :

1. Aktor Admin, Admin mempunyai tugas untuk memasukkan data kecamatan, kelurahan, data data kegiatan rutin, data petugas pemantau dan membuat agenda kegiatan

2. Aktor Petugas Pemantau, Petugas pemantau menjalankan pantauan ke lokasi sesuai dengan kegiatan yang yang telah dimasukkan oleh admin

\section{Desain / Perancangan}

Elaboration merupakan tahap untuk melakukan desain secara lengkap berdasarkan hasil analisis. Tahapan ini merupakan pembuatan desain arsitektur sistem yang di usulkan, desain format data, desain database desain tampilan. 


\section{A. Activity Diagram}

Activity Diagram menggambarkan workflow (aliran kerja) atau aktivitas dari sistem atau proses bisnis dari sistem pengguna melihat web berikut Activity Diagram terdiri dari Activity User dan Activity Administrator.

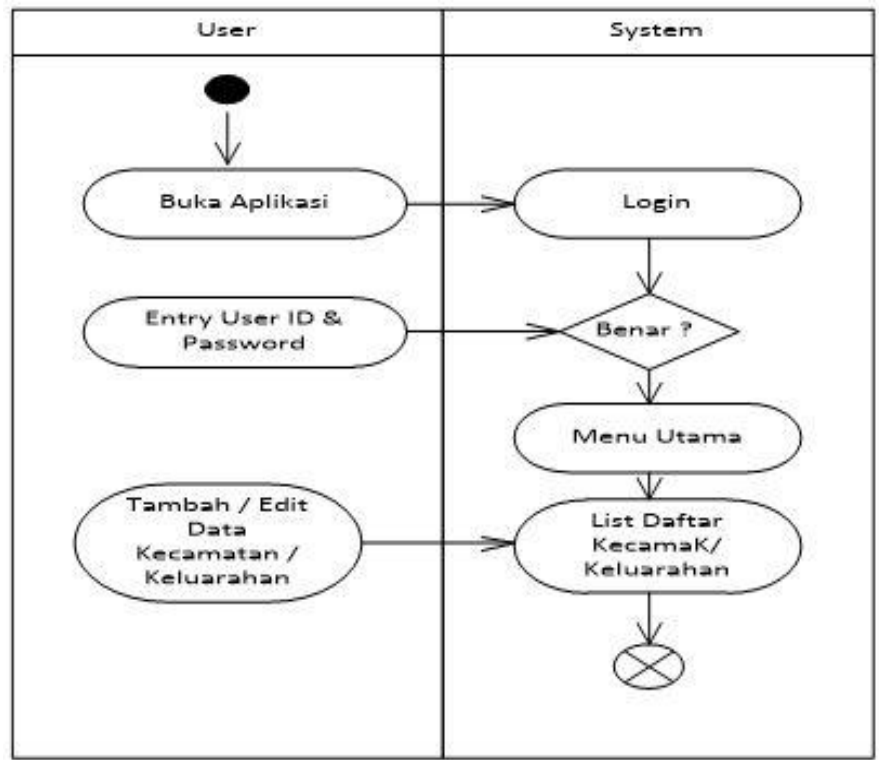

Gambar 2. Activity Diagram Input Data Kecamatan / Kelurahan

\section{Hasil Dan Pembahasan}

Berdasarkan hasil design / Perancangan pada tahap penelitian yang dilakukan penulis, yaitu hasil dan pembahasan dari penelitian ini, adalah menghasilkan rancangan system informasi yang dapat digunakan oleh admin. Peneliti mengimplementasikan rencana tindakan dan harapan dapat menyelesaikan masalah. Selajutnya, setelah model dibuat berdasarkan sketsa dan menyesuaikan isi yang akan ditampilkan berdasarkan kebutuhan user atau pengguna. Hasil kegiatan dan tahapan-tahapan pengembangan system yang telah dilakukan berupa suatu system dari rancangan-rancangan yang telah diuraikan pada bab sebelumnya yang terdiri dari desain file, desain input, dan desain ouput.

\section{Halaman Login Admin}

Halaman menu login digunakan oleh admin untuk masuk kedalam system dengan memasukkan user id dan password. Berikut bentuk form login seperti gambar dibawah ini:

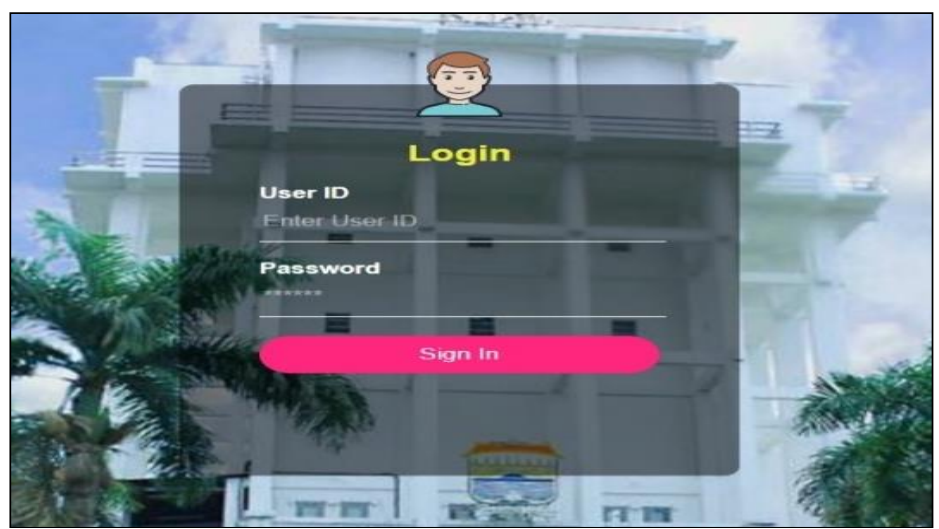

Gambar 3. Halaman Login User 


\section{Halaman Dashboard Admin}

Halaman dashboard merupakan halaman awal yang muncul sebagai halam pembuka dari sebuah sistem.

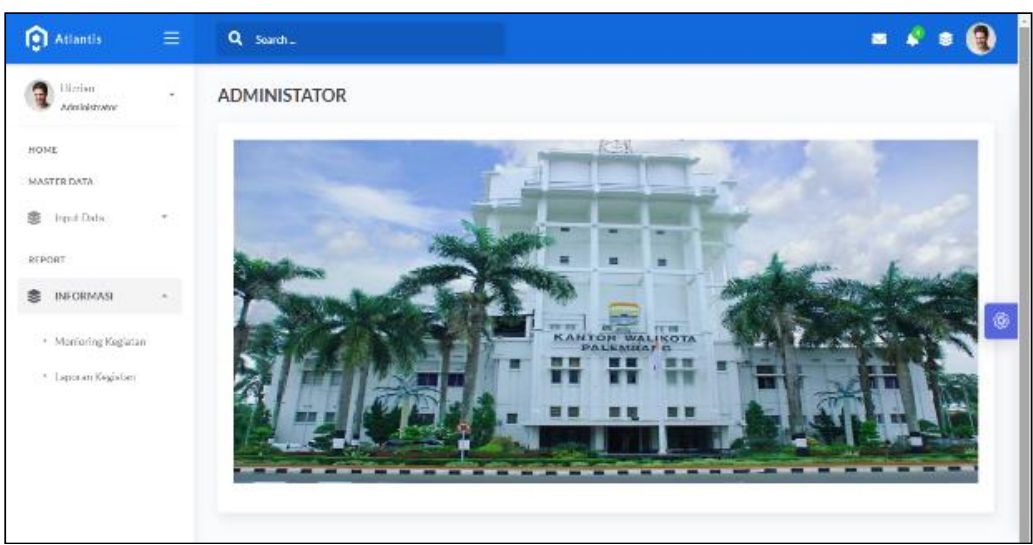

Gambar 4.2 Halaman Beranda

\section{Halaman Daftar Kecamatan}

Halaman daftar kecamatan merupakan halaman yang digunakan untuk menampilkan daftar kecamatan yang dijadikan objek penelitian. Bentuk tampilan adalah sebagai berikut :

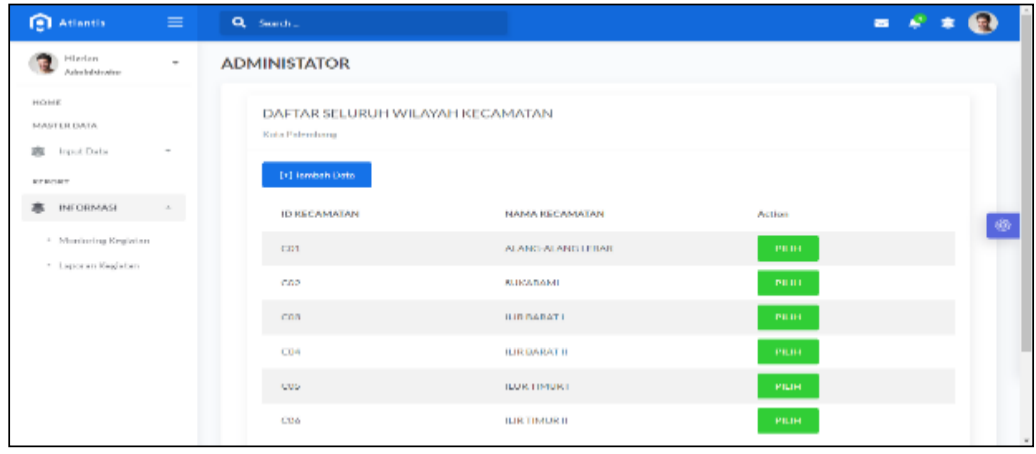

Gambar 4.3 Daftar Kecamatan

\section{Halaman Form Input Kecamatan}

Form input kecamatan digunakan oleh admin untuk mendata kecamata yang ada di kota Palembang.

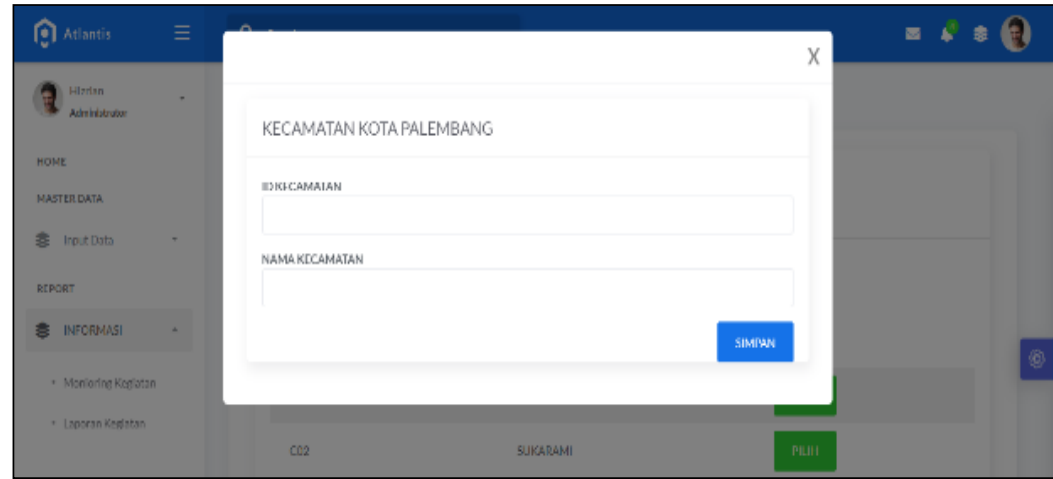

Gambar 4.4 Form Input Kecamatan 


\section{Kesimpulan}

Berdasarkan dari hasil penelitian ini, dapat disimpulkan bahwa :

1. Perangkat lunak monitoring dan pelaporan kegiatan pada dinas kebersihan dan pertamanan merupakan salah satu program yang dapat membantu monitoring dan pelaporan berbasis mobile.

2. Dinas Kebersihan dan Pertamanan Kota Palembang dengan adaya aplikasi yang berbasis mobile ini dapat menyimpan, mengelola dan memproses data dengan cepat data dari hasil surevey dilapangan ke dalam sebuh sistem sehingga informasi nantinya dapat di proses dengan cepat dan akurat.

\section{References}

[1] A.S, Rosa, dan M. Shalahuddin. 2016. Rekayasa Perangkat Lunak Terstruktur Dan Berorientasi Objek. Bandung: Informatika Bandung.

[2] Ahmad Abdillah,2015. Perancangan Sistem Informasi Banjir Pada Jakarta Berbasis Web Dengan Metode User Centered Design jurnal. Buyens. 2014. Seri Panduan Lengkap Mobile Aplication. Yogyakarta.: Andi.

[3] Daulay, Melwin Syafrizal. 2007. Mengenal Hardware-Software Dan Pengelolaan Instalasi Komputer. Yogyakarta: Andi Offset.

[4] H.Heitkotter, S.Hanschke, and Tim A. Majchrzak. 2013. Evaluating Cross-Platform Development Approaches for Mobile Application. Springer Berlin Heidelberg.

[5] Mavrody. 2014. HTML 5, Informatika, Bandung.Purnama,.2014. Mobile Hybrid Aplication, Andi, Yogyakarta.

[6] R Gangundi. 2010. Belajar Sendiri Java Server Pages. Elexmedia, Jakarta.

[7] Ramadhan, 2014. Rancang Sistem Pelaporan Tanah Longsor Di Palembang Menggunakan Metode User Centered Design Jurnal, Informatika, Bandung.

[8] Roger S. Pressman. 2002. Rekayasa Perangkat Lunak Pendekatan Praktisi (Buku Satu). Yogyakarta.

[9] Rosa AS dan M.Shalahuddin. 2015. Rekayasa Perangkat Lunak Terstruktur Dan Berorientasi Objek. Bandung: INFORMATIKA.

[10] Shalahuddin, 2014. Modul Pembelajaran Rekayasa Perangkat Lunak. Modula, Bandung. Sugiyono, 2006, Metode Kualitatif Dan Kuantitatif. Bandung

[11] Sukamto, \& Shalahuddin. 2013. Analisa Dan Desain Sistem Informasi. Yogyakarta: Andi Offset. 
Sengaja Dikosongkan 